Western Washington University

Western CEDAR

\title{
Coproduction or Cohabitation: Are Anonymous Online Comments on Newspaper Websites Shaping News Content?
}

Carolyn E. Nielsen

Western Washington University, carolyn.nielsen@wwu.edu

Follow this and additional works at: https://cedar.wwu.edu/journalism_facpubs

Part of the Journalism Studies Commons

\section{Recommended Citation}

Nielsen, C. E. (2013). Coproduction or cohabitation: Are anonymous online comments on newspaper websites shaping news content? New Media \& Society, 16(3), 470-487.

This Article is brought to you for free and open access by the Humanities at Western CEDAR. It has been accepted for inclusion in Journalism by an authorized administrator of Western CEDAR. For more information, please contact westerncedar@wwu.edu. 
Coproduction or cohabitation: Are anonymous online comments on newspaper websites shaping news content?

\author{
Carolyn E. Nielsen \\ Western Washington University, USA
}

Revised March 17, 2013 as the final version of this paper.

Word count: 8,069 (excluding title page)

This manuscript has not been published and is not being considered for publication by any other print or electronic journal.

Author bio: Carolyn Nielsen is a former newspaper journalist and an associate professor of journalism at Western Washington University. 


\begin{abstract}
The technology that allows readers to post anonymous online comments on newspaper websites gives readers unprecedented opportunities to participate, but poses challenges to the journalistic value of transparency, practice of gatekeeping, and conception of expertise. This nationwide survey of 583 U.S. journalists explores whether the technology has affected their work practices, workplaces, or news coverage. The study, grounded in social shaping of technology theories, finds that journalists are not opposed to sharing their web platforms with readers' comments, but dislike user anonymity and ignore reader input. Despite the technological affordance that provides journalists a means to receive instant, global feedback from readers, journalists are maintaining their jurisdiction over news content and are not participating with readers in mutual shaping. This study finds that journalistic norms and conceptions of expertise prevent journalists from engaging with readers.
\end{abstract}

\title{
Keywords
}

anonymity, online, comments, newspapers, mutual shaping, journalists, interactivity, gatekeeping, technology

Corresponding author: Carolyn Nielsen, Department of Journalism, Western Washington University, 516 High St. MS 9161, Bellingham, Washington, 98225. Email: carolyn.nielsen@wwu.edu 


\section{Coproduction or Cohabitation: Are Anonymous Online Comments on Newspaper Websites Shaping News Content?}

Scholars have asserted that the Internet's ability to broadly allow users an unfiltered and public voice has the power to change journalism (Paulussen and Ugille, 2008; Benkler, 2006; Byers, 2004). Using social shaping of technology theories, this study surveyed 528 U.S. daily newspaper journalists to explore whether U.S. newspaper journalists have been using the technology that enables anonymous online comments on newspapers’ websites to help shape news content. The survey asked whether anonymity affected journalists' views about reader comments, explored the concept of gatekeeping in regard to this technology, and asked whether shifts in work practices and workplace culture were taking place around the technology.

This study sought to answer Boczkowski’s (1999b) call for research to examine media theory and practice in regard to the Internet and mass communication. It used Boczkowski’s (1999b) model for examining Computer-Mediated Communication (CMC) in mass communication to extend the body of research by examining: 1) journalists’ attitudes regarding anonymity of commenters, 2) whether the technology has affected journalists' sense of territoriality in terms of gatekeeping, 3) whether the comments, as new artifacts, have changed newsroom processes, and 4) whether journalists have participated in mutual shaping via the technology. The purpose of this work was to answer the question of whether the technological affordance of online comments, which gave users unprecedented instant, global access to participate, has broadened the one-tomany tradition of newspaper communication, or whether comments have simply 
cohabited newspapers' online platforms. Little work has yet been done to examine anonymous user comments on newspaper websites (Reich, 2011).

Early Social Construction of Technology (SCOT) scholarship presumed that technology affected organizations in predictable and uniform ways (Leonardi, 2009; Boczkowski, 1999a). Leonardi showed how technology shaped and was shaped by organizations in phases via feedback between designers and users. He wrote that technology is mutually shaped when it takes on "a new life in the organization into which it is introduced,” via “negotiations among interested actors” (2009: 292-293). Leonardi called for more emphasis on mutual shaping as a research approach for examining technology in the workplace. This study adopted that approach to answer Boczkowski’s call.

Mutual shaping explores how technology shapes society and society shapes technology via the recursive relationship between user and designer. Sometimes the designer and user share a workplace. Sometimes, as is the case in regard to anonymous online comments, the users are outside of the workplace. This study explored how journalists, as designers of news stories, may or may not have adopted the technology by reading users' comments and/or viewing these artifacts as feedback they use to shape news content. The technology that has enabled online comments provides an interesting avenue for study because its purpose has not been clearly defined and depends upon whose values have been foregrounded. Some newspapers have prohibited their journalists from participating in discussions with readers whereas other news organizations have allowed or even encouraged such interaction. Thus, journalists may have seen comments as a way for readers to make contributions, to allow readers to converse with other 
readers, or as a space to open a conversation between readers and journalists. The values the journalists foreground define the technology's purpose in their workplace.

\section{Review of the Literature}

Boczkowski wrote that in CMC, “technologies’ features and users’ practices mutually shape one another ... The presence or absence of transformations should be treated as a cultural achievement to be explained” (1991: 90-91). This study sought to examine whether transformation was taking place and to explore whether anonymous online comments have created a feedback loop between user and designer, whether the presence of the technology has affected newsroom practices, workplace interactions, or news coverage. This study did not query commenters (users) in regard to their expectations. It focused sharply on the technology's ability to create a new interface between journalists and commenters.

Boczkowski called for scholarship to examine, “(1) the social consequences of the increased anonymity of interlocutors; (2) the reconfiguration of territoriality and interestbased associations; (3) the processes that mediate between the introduction of new artifacts and their social outcomes; and (4) the mutual shaping of consumers and technologies” (1999b: 102). Boczkowski asserted that mutual shaping "is best suited to capture the complexity, unpredictability, and recursivity of the interactions among technological features and users’ discourses and practices” (1999a: 86) and asserted that most research on the computerization of the newsroom has assumed that technological changes have affected news content (2004). This study heeded Boczkowski's advice and did not presume editorial effects. 
In 2004, Boczkowski noted that scant attention had been paid to how new-media technology had influenced journalists' workplaces. Since then, qualitative work has explored this interplay (Karlsson, 2011; Schimtz Weiss, and Domingo, 2010; Singer, Hermida, Domingo, Heinonen, Paulussen, Quandt, Reich, and Vujnovic, 2011). Much of this work has been international in focus (Domingo, 2008; Paulussen, Heinonen, Domingo, and Quandt, 2007). Because press traditions and freedoms vary among nations as do systems of anonymous online comment moderation, this study focused on U.S. newspapers, which share a tradition of seeking objectivity and which have largely outsourced comment management/moderation (MacMillan, 2007). That lack of influence at the level of moderator makes the link between user and journalist more direct. This study followed the fifth of Reich's (2011) five approaches from which to examine usergenerated content in the mass media. That approach "explores the perception of comments among journalists, including their management of procedures” (p. 195). Newspapers and Online Interactivity

Anonymous online comments represent one aspect of the broader concept of interactivity that has become part of newsroom conversations. Online interactivity is a relatively new concept in the centuries old field of print journalism. In 1996, only about 15 percent of newspapers had an online presence (Ash, Halpern, and Hettinga, 2009). By 2009, most daily newspapers — even small ones — had websites (Singer and Ashman, 2009). Newspapers have historically been a one-to-many information medium limiting interaction with local readers to personal phone calls, signed letters to the editor, or, more recently, emails to individual journalists. New technology has afforded unprecedented opportunities for reader participation, including enabling anonymous users' participation. 
Journalists have been generally resistant to interactivity as it challenges their traditions of gatekeeping and conception of professional identity (Deuze et al., 2007).

Paulussen and Ugille wrote:

It is argued that professional journalists will increasingly have to share their control over the news production process with their users, who are becoming more and more actively involved in the creation of content. This could not only result in an increased use of user-generated content by journalists, but it could also stimulate collaboration between professional and amateur journalists. In other words, journalism will fundamentally shift from a top-down lecture to an open conversation (2008: 24-25).

“Interactivity” gave readers/users the ability to customize content or provide feedback (Byers, 2004). Gane and Beer (2008) described interactivity in new media as “manipulable” in terms of machine-machine interaction, human-machine interaction and human-human interaction. Boczkowski defined interactivity as "the use of many-to-many and one-to-one communication spaces such as forums, chat rooms, and user-authored sites, in addition to the one-to-many mode of traditional media” (1999b: 199). This study focused on the interactive practice that has allowed users to share their opinions via anonymous online comments. Reich (2011: 191) noted "are still in their infancy and have received only limited attention from scholars so far.”

Previous studies found that online forums on newspaper websites generated high levels of user (reader) participation (Boczkowski, 2004; Reich, 2011). At the time Boczkowski’s 2004 book, Digitizing the News: Innovation in Online Newspapers, was published the technology enabling anonymous comments to share screen space with individual articles (rather than in separate chat rooms) was just coming into use. This survey sought to examine a specific practice not widely in place at the time of Boczkowski’s study. 
Anonymity On The Newspaper Platform

The adoption of online comment technology on newspaper websites made it possible for users anonymously assert their opinions on the news platform. This study defined technological affordance as the way technology has made participation easier when compared to previous tools. This definition is important because readers have always had the ability to give journalists feedback, but the new technology made possible instant, global access that could be seen by all users and designers. Anonymity in these forums has been a value choice with pros and cons. "News sites must strike a delicate balance when deciding whether to allow those who comment to remain anonymous: To attract users, sites want to make it as easy as possible for people to participate, and anonymity allows users to feel less inhibited when they comment” (Gsell, 2009).

The Reduced Social Cues model has shown how online users enjoyed a sense of equalized participation and status because their identities were concealed, protecting them from social judgments based gender, age, race, class, etc. The other side of the model has been that individuals were depersonalized and the social norms that facilitate civility have disappeared. In audience anonymous online interaction with journalists, there is an increased opportunity for reader participation and a decreased opportunity for journalists to evaluate a commenter's perceived credibility. In a profession where the adage has long been, "If your mama says she loves you, check it out,” skepticism is embraced and transparency is a strongly held value. The Society of Professional Journalists Code of Ethics has warned journalists to be to put a premium on the importance of identifying sources, to test the accuracy of information, and to question the motives of people who seek anonymity. While commenters are not sources in news 
stories, their comments appear on the same screen as the news articles and may seek to add details, correct inaccuracies in a news story, or add unverified or untrue information alongside the journalist’s work. Reich (2011: 189) wrote, “Web designers usually separate user comments from journalistic content in one or more ways, such as by their physical placement on the page, their hierarchical relationship to news items or their typographical presentation. But, in reality, the two types of content are inseparable. Online items without comments are becoming rare and starting to look awkward, even suspicious.”

\section{Territoriality: Gatekeeping and Professional Identity}

Fourteen years ago, well before the existence of anonymous online comments on newspaper websites, Williams wrote, "In a world where everyone can be a publisher, journalists are vulnerable to losing their franchise as gatekeepers of news” (1998: 34). Yet, Benkler (2006) found that most readers are still clustered around a small group of trusted websites for most of their information. Deuze, Bruns, and Neuberger (2007) noted that interactivity has threatened journalists' sense of professional identity and their ability to be gatekeepers. Domingo’s (2008) study of four Spanish newsrooms noted what he called a "myth of interactivity" that is "embedded in the mindset and discourses" (p. 681) of journalists. Domingo found journalists responded positively to the concept of interactivity, but because of work-practice routines, journalists working for traditional newspapers (rather than online-only news sites) viewed "audience participation as a problem to manage rather than a benefit for the news product” (p. 689).

The process of gatekeeping within the newsroom describes how journalists filter and select information for audiences based on what they deem "newsworthy.” In 
newspaper newsrooms, for example, a wire editor scans through hundreds of headlines from the Associated Press and decides which are most pertinent; or a reporter receives a news tip over the phone and decides, based on the perceived credibility of the caller or information, whether to check it out. This filtering takes place at many levels as news moves from “raw” to “complete” (Shoemaker and Vos, 2009). As Boczkowski wrote, "Issues of information flows relate to the character of newsroom practices. All occupations and professions have certain traits that make them stand apart as a distinctive domain of activity. For modern journalism, one such trait is gatekeeping” (Boczkowski, 2004: 206-207).

Questions about gatekeeping were salient in regard to this study of anonymous online comments because the journalist as filter has been removed. The nation's largest media ownership groups have outsourced their newspaper comment management to third parties, taking them entirely out of the hands of the newsroom (MacMillan, 2007). Some newspapers have tried to make anonymous users more accountable for their comments by requiring users to register before they can post comments (Gsell, 2009). However, identities have not been verified and could be made untraceable.

Hermida and Thurman's (2008) study of 12 national newspaper websites in the United Kingdom revealed editors’ concerns about users’ contributions damaging their newspapers' reputations. The idea of publishing a comment without vetting it was described as "very dangerous." In one of the most recent studies of user contributions on newspaper websites, Singer wrote:

Editors have made room for users on their Web sites but still have their elbows out when it comes to sharing not just space but also occupational roles... The literature suggests that through journalists are increasingly likely to say they view news creation as a partnership with people outside 
the newsroom, the reality is that they still see what they do as distinct from what users do. That is, they continue to see boundaries around roles even as they acknowledge the dissolution of boundaries around the means of enacting those roles” (2009: 830).

In Singer's study of presidential election coverage on newspaper websites, editors listed "user contributions" as a source of pride only $2.4 \%$ of the time, down from $14.7 \%$ when that study was conducted in 2000 (Singer, 2009). Singer concluded, “Anyone can provide space for Internet users, and anyone can fill the space once it is provided. These journalists seem to be asserting the importance of a role that is their own historical franchise—and underscoring its value in a turbulent media environment” (2009: 838).

Boczkowski asserted that “print’s disregard for reader-authored content” begins in journalism education and is reinforced through workplace culture (2004: 206). An editor in Boczkowski’s 2004 study described his newspaper’s online forums as a “gathering place” for readers. This mirrored previous studies that have found newsroom culture instills a sense of “professional distance” (Deuze, 2003).

Deuze’s assertion was affirmed in a 2010 study that measured journalists’ perception of professional role in regard to online comments (Nielsen, 2012). That study built on decades of role-perception studies that have historically found that journalists have primarily valued the investigative/interpretive role (Beam, Brownlee, and Weaver, 2009). When measuring journalists' role perception in regard to anonymous online comments, that study found that journalists took on the disseminator role, thus enforcing traditional one-way communication. How journalists conceptualize their professional roles in regard to anonymous online comments may inform their attitudes toward participating in mutual shaping via this technology.

Online Comments and Social Processes in the Newsroom Workplace 
The same technology introduced into different work environments has been shown to have different impacts, meaning the workplace, rather than the technology, determined whether or how a new technology has affected change (Barley, 1986). Mutual shaping of technology in the workplace, where hierarchy has elevated the role of designer over that of the user (Barley, 1986; Bechky, 2003) has often been subjected to designers’ concepts of knowledge, legitimacy, and authority (Bechky, 2003). This has preserved hierarchy when feedback was given but ignored because the user was seen as lacking in legitimacy, knowledge, and/or authority. This study considered journalists with formal education and experience as designers of the news. Commenters are users who have been given the ability weigh in on errors, offer different perspectives, or notify both designers and users of "bugs" or flaws in news stories. Questions of occupational jurisdiction have played a key role in mutual shaping in the workplace (Barley, 1986; Bechky, 2003; Orlikowski, 2000; Orlikowski and Yates, 2006). Mutual shaping did not occur when the designer dictated it would not. The group with most formal education and institutional prestige had "the power to determine when the other communities could participate in the design process” (Bechky, 2003: 736). Thus, mutual shaping would not be possible if journalists ignored comments, did not consider them as feedback, or didn’t see content produced by “amateurs” as legitimate. This echoes Feenberg’s (1999) assertion that technology itself empowers the designer to maintain dominion over the user. Feenberg argued that technologies have been used to manifest control, and have been imbued with the motives of their designers. Mutual Shaping: The Interface Between Designers and Users 
Studies of "old technology" (Fischer, 1994) such as the telephone showed how people reacted with a sense of technological determinism, seeing the technology as a foreign device invading the home. The focus was on the technology, and the role of the user in shaping it was limited and passive. More recent society and technology studies showed how the user gained a more active role in mutual shaping by foregrounding his or her values to use a technology in a different way, or in a way that encouraged designers to materially alter a technology to meet different needs (Kline and Pinch, 1996; Pacey, 1983; Pinch and Bijker, 1984). Users, in a limited way, shaped the same stabilized technology to meet different needs. After stabilization, users continued to influence design changes, but modifications became increasingly minor, then stopped (Pinch and Bijker, 1984). At that point, users' shaping role in that technology ended. Technology reached closure when a specific group’s social needs were met (Pinch and Bijker, 1984).

A technologically deterministic approach to studying anonymous online comments in the newsroom would begin with the assumption that the technology had changed work practices and social interactions around anonymous online comments. Studying the issue from a mutual shaping perspective allowed this research to explore whether this was the case.

\section{Research Questions}

The research questions for this study came from Boczkowski's 1999 call for scholarship examining CMC phenomena and mass communication (see Review of Literature).

RQ1 What are journalists' perceptions about the anonymity of the online interlocutors? 
RQ2 Is the technology reconfiguring territoriality, specifically the practice of gatekeeping?

RQ3 Is the introduction of new artifacts (online comments) affecting social outcomes in the newsroom workplace?

RQ4 Is recursive sharing between designer and user via this technology occurring?

\section{Methodology}

This survey was conducted during February and March of 2010 as a Web-based survey, which has been found to be an effective tool for querying journalists, many of whom work remotely or in shifts and spend a good portion of the day using computers (Woong and Trumbo, 2000). A random, stratified sample representing small, mid-sized, and large circulation daily newspapers was conducted using the 12 Society of Professional Journalists (SPJ) geographic regions and three circulation-size categories. SPJ defines circulation categories as: small $(1-50,000)$, mid-size (50,0001 to 100,000) and large $(100,000+)$. A list of all daily newspapers in each region was complied using the Editor and Publisher International Year Book. Newspapers were divided by region and size, and then assigned numbers. A Web-based randomizer tool generated 36 sets of random numbers. The resulting sample consisted of 36 newspapers — a small, a midsize, and a large-circulation newspaper in each SPJ region. Each newspaper's website was checked to ensure it allowed anonymous online comments. This stratification allowed insight into whether newsroom size influenced attitudes and/or work practices. Because this study sought to examine workplace attitudes, entire newsrooms, rather than individuals were selected. Further, online comments can go beyond a reporter's work to 
affect copy editors, section editors, and managers. The survey was pretested on former newspaper journalists and working newspaper journalists outside of the sample.

An email introduction containing a link to the SurveyMonkey survey was sent to the 2,900 journalists in the sample via individual email addresses obtained from their newspapers’ websites, which listed email addresses and job titles for every newsroom staff member. In three cases, editors distributed the survey to the appropriate staffers via the company's internal email list, then reported to the author how many journalists received the survey. Photographers and videographers were excluded from the sample because the survey focused specifically on comments about articles, not images. The survey asked respondents to identify their circulation category sizes and job titles.

Of the 2,900 surveys emailed, 134 were returned as undeliverable and another 133 automated email responses indicated journalists were on vacation or furlough. Because the survey was anonymous, it was not possible to track who responded. Excluding those who specified being on vacation/furlough, 2,633 people received the survey. Of those, 1,683 were sent to journalists from large newspapers, 567 went to mid-size papers and 383 went to small newspapers. After 10 days, an email reminder was sent to the 2,766 valid email addresses. Ultimately, 647 journalists participated in the survey, making for a 25 percent response rate. The response rate is consistent with or higher than other Webbased surveys of journalists (Cassidy, 2007; Cassidy, 2005; Johnson and Kelly, 2003; Machill, Beiler, and Johannes, 2009; Wheeler, Christiansen, Cameron, Hollingshead, and Rawlins, 2009). Small newspapers had the highest response rate (30 percent), followed by large newspapers (25 percent), then mid-size newspapers (21 percent). Of the 647 
journalists who began the survey, 582 finished it. Following Reindardy’s (2009) model, studies that were less than 30 percent complete were excluded.

Responses were based on five-point Likert scales. Each question also allowed for participants to provide narrative information. This survey sought to measure habits and attitudes rather than to quantify things such as time spent doing a specific activity. Because the dynamic nature of journalists’ jobs, every day is different and journalists’ practices vary depending upon news cycle and workload. Therefore, this study employed qualitative response options such as "sometimes” and "frequently” to measure habits, and options such as “strongly agree” versus “strongly disagree” to gauge opinion. Some questions dealt with habits and practices surrounding use of online comment technology, but the survey acknowledged that not all journalists have adopted the technology, so those who had not indicated "not applicable" to questions of use. All journalists answered all questions in regard to attitude toward online comments.

RQ1 was informed by a single survey question that asked journalists to respond to the statement “Online comments should not be anonymous.” This question measured journalists’ attitude toward anonymity without conflating views on anonymity with journalists' perceptions about the quality of the comments or conceptions of the user.

Three questions about journalists’ attitudes informed RQ2. The survey asked journalists to respond on a five-point Likert scale from strongly disagree to strongly agree to the following statements that informed conceptions of territoriality: online comments should not be allowed, journalists should not respond to online comments, and journalists should respond to correct factually inaccurate comments. These questions sought to gauge whether journalists were territorial about sharing their platforms (addressing 
territoriality separately from anonymity), whether journalists felt they should engage in dialog with readers or viewed comments as a conversation/feedback loop, and whether journalists felt they should assert their professional voice of authority to correct inaccuracies in users' comments.

Three survey questions informed RQ3. To measure potential influences on workplace interactions involving the hierarchy from reporter to editor, journalists were asked whether editors were adding material to articles to address anticipated online comments or deleting material from articles in an effort to avoid anticipated online comments. These questions were specific to online comments because editors regularly add or cut material from news articles for reasons of space or clarity. The survey questions that informed attitude had to do with the sometimes-contentious relationship between reporters and editors. These questions asked whether online comments caused mistrust between reporters and editors and were used to show whether editors were using reader comments to question reporters’ work.

Four questions informed mutual shaping in RQ4 and sought to ascertain whether journalists were open to the idea of mutual shaping as well as to explore the question of whether reading comments was a worthwhile use of time. Two questions measured practices and asked whether comments had offered journalists a perspective they had not considered and whether online comments had changed the way journalists worked on a story. This showed whether contributions from "amateur” users were considered useful as well as whether they were considered feedback for journalists.

Two questions measured attitudes and asked journalists whether reading online comments took time they should be spending working on stories and whether reading 
online comments increased journalists’ job satisfaction. These questions were paired because if a technology makes one's job easier and/or more enjoyable, it would be less likely to be viewed as a time drain. Further, they showed whether journalists were open to mutual shaping.

\section{Findings}

Following Boczkowski’s model, the study sought to examine journalists’ perceptions of and interactions with online comments with regard to anonymity, territoriality, social processes around new artifacts in the workplace, and mutual shaping. It is important to note that this study began by measuring adoption level of the technology rather than presuming it was widely used. Mutual shaping is not a technologically deterministic theory.

In terms of adopting the technology, meaning the frequency with which journalists read anonymous online comments on articles they wrote or edited, $35.8 \%$ of journalists reported that they "frequently” or "always” read comments on their own work, 29\% reported they "sometimes" read comments on their work, and 35.2\% reported that they "rarely” or "never" read comments on their work. While analysis using inferential statistics would not be appropriate for this qualitative survey data, Spearman's rho found no significant correlations between journalists’ habits with reading online comments and their attitudes toward online comments (See Table 1).

\section{RQ1: Anonymity of Interlocutors}

Per Boczkowski’s model, RQ1 explored whether user anonymity was a factor influencing journalists’ attitudes toward anonymous online comments; 73\% somewhat or 
strongly agreed with the statement “Online comments shouldn’t be anonymous,” 18\% were neutral and 9\% slightly or strongly disagreed with that statement.

Most of the narrative responses given in response to this statement took the view that anonymity had unfairly given commenters protection not given to journalists, sources, or people who wrote signed letters to the editor. One reporter wrote, "I strongly believe anonymous commenting, especially unmoderated, not only adds little to the public discourse but cheapens it to the level of a washroom stall.” Another wrote, "Turn over the rock of anonymity the online bigots and fools hide under and the problem is solved. Isn't that the essence of journalism? Shine a light on injustice and ignorance and it may shrink away.”

One reporter wrote that anonymous online comments a newspaper's reputation: “The biggest problem with online comments is that anonymity is allowed. Because of that, those who post are free to lie and vent without accountability. The result is that online comments sabotage the credibility and dignity of the entire news organization.” RQ2 Territoriality and Gatekeeping

RQ2 asked whether technology was reconfiguring territoriality, specifically in regard to gatekeeping.

Results showed journalists supported the concept of users posting online comments with 58\% slightly or strongly agreeing that online comments should be allowed on newspaper websites, 23\% neutral, and 19\% slightly or strongly disagreeing. Journalists were divided over the question of whether they should respond to online comments; $45 \%$ slightly or strongly agreed they should not respond, $22.2 \%$ were 
neutral, and 32.8\% slightly or strongly disagreed. Most of the narrative responses, such as this one, stated that interacting with commenters was not a journalistic value:

Reporters and editors should respond rarely to online comments. The exceptions should be when the comments contain threats or factual distortions of the published work. While comments are supposed to spark conversation, a reporter/editor can become enmeshed in the conversation to the detriment of his/her primary role — doing the journalism. Also, experience has shown that readers are more interested in commenting on the facts of a story and arguing with one another than in conversing or arguing with the person who wrote the story.

Journalists felt strongly that they should respond to set the record straight in regard to factually inaccurate comments; $75.3 \%$ of journalists slightly or strongly agreed, $13.1 \%$ were neutral and $11.6 \%$ slightly or strongly disagreed.

\section{RQ3 New Artifacts and Workplace Interactions}

RQ3 examined whether new artifacts (online comments) related to the technology were affecting social outcomes in workplace interactions between reporters and editors. As to whether editors were adding material to articles to address anticipated online comments, $76.1 \%$ said never or rarely, $18.5 \%$ said sometimes, and 5.4\% said often or always. As to whether editors were deleting material from articles in an effort to avoid anticipated online comments, $77.5 \%$ said never or rarely, $12.5 \%$ said sometimes, and $10 \%$ said often or always. In regard to whether online comments caused mistrust between reporters and editors, $88.3 \%$ said never or rarely, $10 \%$ said sometimes, and $1.7 \%$ said often or always.

Narrative responses showed that editors and reporters did not talk about online comments and that the technology played little or no role in newsroom discussions or decisions. Journalists’ responses supported the view that comments had nothing to offer, were not thoughtful, were not on-topic, and/or were written by a vocal minority of voices 
that did not reflect the broad readership. One editor who reads online comments said that comments challenging a reporter's work might generate a discussion between an editor and a reporter, but that the editor would still back the reporter because of the reporter's expertise: "We talk it over with the reporter, but generally stand by her or his recollection and notes. As a result, many online responders declare deepened distrust of the paper's accuracy and perceive a slant to coverage.”

\section{Mutual Shaping and Work Patterns}

RQ4 asked whether journalists had viewed the technology as a means for recursive sharing between users and designers and whether it had changed journalists’ work patterns. Results showed that lack of time was not a reason journalists forego reading comments; $55.1 \%$ of the sample said that time drain was never or rarely the issue, $33.4 \%$ said it was sometimes the case, and $11.5 \%$ said that was often or always the case. In terms of whether journalists felt reading online comments increased their job satisfaction, the majority of journalists, $66.1 \%$, said this never or rarely happened, $29.5 \%$ said it sometimes happened, and $4.1 \%$ said it frequently or always happened.

A question asking whether journalists felt users’ comments showed them a new perspective sought to get to the heart of whether journalists were open to the idea of participating in mutual shaping with readers. While $53.5 \%$ of journalists responded that comments sometimes showed them a new perspective, only $8.4 \%$ said that frequently or always happened and 38.1\% said that rarely or never happened.

Finally, the study asked if reading comments led journalists to change how they worked on stories. A large $87.8 \%$ of the sample said comments never or rarely affected how they reported or edited articles. As one reporter bluntly stated, “Are you kidding? 
We have old-fashioned journalism standards at our newspaper. Why would we bend or amend those for the sake of a mindless rabble? Now, as always, we craft our stories to meet the needs and to avoid insulting the intelligence of our readers.” One reporter wrote, “It doesn't change how I do my job. I see it this way: A brain surgeon wouldn't ask advice from an untrained patient. We are the professionals. The readers, as their comments reveal, are often ignorant of the facts and usually lack the context that a beat reporter brings to a story.”

While narrative responses and mean scores showed journalists as dismissive of the idea the comments would affect the workplace, some reporters did indicate changing their work practices to try to head off anticipated comments. One reporter wrote:

I'm much more careful, for example, to avoid situations that might lead to opportunities for some of our regular commenters to make racist or other such comments. For example, when writing about someone who has benefited from a social service or charity program, I now always and especially if the person is black or Hispanic - mention what he or she does for a living, so that it is clear he/she does work (or have worked, if the person is disabled).

At a newspaper where the reporters are allowed to edit/remove comments, one reporter wrote about concerns that readers might not distinguish between a journalist's work and readers’ racist comments:

I often track some of my stories in order to remove abusive comments or stop the comment process altogether. This happens primarily in crime stories, particularly murders of young black men in our largely urban market, so that family members and others don't see racist remarks that gloat over a death. This is done partly out of sympathy to the family and partly, based on my experience, because the family may not distinguish between the reporter who comes to their door and the anonymous person whose remarks follow my story. 
Bigotry, sexism, and racism in online comments were common concerns raised by journalists in narrative responses across all categories of this study as well as in Reich's 2011 study.

\section{Data Limitations}

This study sought to measure journalists’ adoption of the technology (meaning how frequently they read comments) relative to how long the technology existed in their newsrooms. However, 37.5\% of respondents did not know how long their newspapers had used the technology, so it was not possible to examine level of use and length of exposure to the technology.

\section{Discussion}

The finding that journalists disliked the anonymity of online comments was not surprising given the profession's long-held skepticism toward anonymity. However, journalists’ strong support for readers' ability to post comments on newspaper websites provided insightful context that helped parse questions regarding territoriality and occupational jurisdiction. For example, journalists were open to sharing the platform, but wanted transparency and demanded accuracy in comments. Journalists felt they should participate not by engaging with readers but by intervening to correct inaccurate usergenerated content. While not gatekeeping in the traditional sense of preventing publication, this is a reassertion of territoriality regarding who journalists feel has the right to disseminate information. Therefore, journalists have not foregrounded interaction with readers, they have foregrounded their commitment to accuracy, their sense of occupational jurisdiction, and their conception of expertise. 
Journalists indicated that devote little time to reading comments because they don't feel reader comments have much to offer in terms of showing them new perspectives. This “absence of transformation” as Boczkowski (1999b) called it, may best be explained by journalists’ conceptions of knowledge, legitimacy, and authority. The fact that comments are not seen as affecting editor-reporter relationships because editors were not using the technology or its artifacts to exercise workplace dominion may also reinforce that assertion. If editors felt users had something to contribute that would be beneficial to shaping news content or felt that users' opinions carried weight that would strengthen or "debug” news stories, they would find the technology useful and the technology would play a role in mediating between editors and reporters. There is no shortage of critique of journalists' work in comments, yet editors have conveyed that they trust reporters more than readers.

Finally, while journalists were not trying to exclude readers/users from news platforms, they were not engaging with readers in mutual shaping or drawing on users to coproduce news. The ability of interactive online technology to broaden of the conversation in a traditionally one-to-many communication medium has been cited as one of the chief benefits of the Internet by scholars such as Benkler, who has asserted that the Internet has the potential to improve journalism. However, this has not happened in regard to anonymous online comments on newspaper websites.

Journalists do not see value in the amateurs' contributions via anonymous online comments. One editor wrote, “Gaining new sources or expertise [from online comments] happens, but it's rare — and welcome. Most reporters don't have the expertise that people 
in the field have. Most commenters, though, don't have the reporters' level of discernment.”

One reporter summed up what most said:

“...our online commentators have little to offer anyone. They seem to be either morons or pranksters. I can't imagine any serious journalist worrying, or taking a cue from, an online post. Readers who take the time and effort to compose letters to the editor, or to send me a personal e-mail typically have something to offer."

Some narrative responses indicated that online comments occasionally provided helpful feedback, but were not worth the cost of the negative aspects that accompanied them. For example, one reporter wrote:

I've occasionally gleaned tips from online comments and have also used them to build relationships with readers, who sometimes reciprocate down the road with tips or story suggestions. Those interactions make the process worthwhile. But at least half — often more — of the comments on a story tend to be 'me, too' remarks, bad jokes, personal gripes or faceless attacks on the people mentioned. A story on an infant's death at the hands of a mother's boyfriend, for example, tends to lead to extended discussions between commenters about single motherhood, interracial relationships, welfare or simple personal attacks. I'm not sure what a newspaper can do about this problem, since I don't think a journalism outlet should be in the business of censoring discussion.

\section{Conclusion}

Boczkowski (1999b) called for examining CMC in regard to journalism in the digital age model by examining journalists’ attitudes about commenters’ anonymity, exploring whether the technology has affected journalists' sense of territoriality in terms of gatekeeping, asking whether the comments, as new artifacts, have changed newsroom processes, and ascertaining whether journalists have participated in mutual shaping via the technology. This study found that mutual shaping was not taking place, largely because of the journalists' conception of the user. However, the cloak of anonymity may 
be a facet of a more complex answer. The social consequence of anonymity was conflated with journalists’ notion of territoriality and conceptions of expertise. For example, journalists were not opposed to readers sharing the news platform, but they were most strongly opposed to inaccurate information in user comments. Thus, journalists may not "have their elbows out” so much as Singer (2008) found, but inaccurate information in comments was a strong trigger for reassertion of territoriality. Thus, the study found that the technological affordance strengthened journalists' territoriality in regard to users, but the artifacts did not change newsroom processes or pose challenges in newsroom relationships.

Mutual shaping could have occurred around the technology if the journalists had adopted the technology, meaning they read the comments and used them for further reporting. Mutual shaping did not take place because journalists largely ignored user input. This study found that journalists felt anonymous online comments were primarily a forum for readers to interact with other readers. Journalists were largely not using the technology for versioning based on user input. This absence of transformation may best be explained by the fact that mutual shaping could not take place because the designers were not willing to participate.

Pinch and Bijker (1984) wrote that when technology reached stabilization, the role of the user decreased and then stopped. Closure was achieved when a social group’s needs were met. Because journalists largely supported the idea of having online comments, but didn't read them, this suggests that journalists viewed comment spaces as a third place for readers. Using this conception, technology had satisfied users’ needs, making it a closed technology rather than a tool for mutual shaping. While users may 
have participated in ongoing versions of comments by conversing with other readers, journalists maintained the "we publish, you read" mentality. Technology, in this case did not take on "a new life in the organization" via "negotiations among interested actors" (Leonardi, 2009: 292-293) because most journalists were not interested and not negotiating.

While others (Benkler, 2006; Byers, 2004;Paulussen and Ugille, 2008) have viewed the Internet as a technology with unprecedented ability to empower users, this study found that journalists still viewed users as consumers rather than coproducers. Although Paulussen and Ugille (2008) described how user-generated content could turn journalism into a conversation rather than a top-down lecture, this study did not find that occurring in regard to anonymous online comments. This study concludes that journalists have viewed readers not as coproducers, but rather as users cohabiting the platform.

\section{Idea for Future Study}

Several study participants mentioned a practice unanticipated by this study — editors turning off the anonymous online comment function for certain stories because they feared vitriolic comments. The disabling of comments speaks to territoriality and mutual shaping. Journalists in the survey may not have viewed disabling comments as affecting the way they work on a story, but it did indicate an awareness of the technology, an attention to its potential impacts, and an exercise of gatekeeping power. 


\section{References}

Ash E, Halpern D and Hettinga K (2009) Effects of a Trend: The Influence of User Comments on Readers' Perceptions of Online Newspapers. Unpublished conference paper, Association for Education in Journalism and Mass Communication, Boston, MA, August 2009.

Barley SR (1986) Technology as an Occasion for Structuring: Evidence from Observations of CT Scanners and the Social Order of Radiology Departments. Administrative Science Quarterly 31(1): 78-108.

Beam RA, Brownlee BJ and Weaver DH and (2009) Changes in Professionalism of U.S. Journalists in the Turbulent Twenty-First Century. Journalism and Mass Communication Quarterly (86)2: 277-298.

Bechky B (2003) Object Lessons: Workplace Artifacts as Representations of Occupational Jurisdiction. American Journal of Sociology 109(3): 750-752.

Benkler Y (2006) The Wealth of Networks: How Social Production Transforms Markets and Freedom. New Haven, CT: Yale University Press.

Beyers H (2004) Interactivity and Online Newspapers: A Case Study on Discussion Boards. Convergence 10(4): 11-20.

Boczkowski PJ (1999a) Mutual Shaping of Users and Technologies in a National Virtual Community. Journal of Communication 49(2): 86-108.

Boczkowski PJ (1999b) Understanding the Development of Online Newspapers. New Media \& Society 1(1): 101-126.

Boczkowski PJ (2004) The Processes of Adopting Multimedia and Interactivity in Three 
Online Newsrooms. Journal of Communication 54(2): 197-213.

Cassidy WP (2005) Variations on a Theme: the Professional Role Conceptions of Print and Online Newspaper Journalists. Journalism and Mass Media Quarterly 82(2): 264-280.

Cassidy WP (2007) Online News Credibility: An Examination of the Perceptions of Print and Online Newspaper Journalists. Journalism and Mass Media Quarterly, 82(2): 264-280.

Deuze M (2003) The Web and Its Journalisms: Considering the Consequences of Different Types of Newsmedia Online. New Media \& Society 5(2): 203-230.

Deuze M, Bruns A and Neuberger C (2007). Preparing for an Age of Participatory News. Journalism Practice 1(3), 322-338.

Domingo D (2008) Interactivity in the Daily Routines of Online Newsrooms: Dealing with an Uncomfortable Myth. Journal of Computer-Mediated Communication (13), 680-704

Feenberg A (1999) Questioning Technology. London: Routledge.

Fischer CS (1994) America Calling: Social History of the Telephone to 1940. Berkeley, CA: University of California Press.

Gane N and Beer D (2008) New Media: The Key Concepts. Oxford, UK: Berg. Gsell L (2009, February/March) Comments Anonymous. American Journalism Review, $16-17$.

Hermida A and Thurman N (2008) A Clash of Cultures. Journalism Practice 2(3): 343356.

Karlsson M (2011) The Immediacy of Online News, The Visibility of Journalistic 
Processes and a Restructuring of Journalistic Authority. Journalism 12(3): 279295.

Kline R and Pinch T (1996) Users as Agents of Technological Change: The Social Construction of the Automobile in the Rural United States. Technology and Culture 37(4): 763-795.

Leonardi P (2009) Crossing the Implementation Line: The Mutual Constitution of Technology and Organizing Across Development and Use Activities. Communication Theory 19(3): 277-310.

Machill M, Beiler M and Johannes G (2009). How Do Journalists Do Research on the Internet? An Observation and a Survey on the Research Performed by Journalists Working for Daily Newspapers, Radio, Television, and Online. Unpublished conference paper, International Communication Association, Ipswitch, Mass, June 2009.

MacMillan R (2007) MediaNews Uses Topix for Online Newspaper Comments.

Reuters.com, 27 November 27. http://www.reuters.com/article/idUSHO72369020071127 (accessed 20 March 2010).

Nielsen C (2012) Newspaper journalists support online comments. Newspaper Research Journal 33(1): 86-100.

O’Sullivan J and Heinonen A (2008) Old Values, New Media: Journalism Role Perceptions in a Changing World. Journalism Practice 2(3): 357-371.

Orlikowski WJ and Yates J (2006) ICT and Organizational Change. Journal of Applied Behavioral Science 42(1): 127-134. 
Orlikowski W (2000) Using Technology and Constituting Structures: A Practice Lens for Studying Technology in Organizations. Organizational Science 4(11): 404428.

Pacey A (1983) The Culture of Technology. Cambridge, MA: MIT Press.

Paulussen S and Ugille P (2008) User Generated Content in the Newsroom: Professional and Organisational Constraints on Participatory Journalism. Westminster Papers in Communication and Culture 5(2): 24-41.

Pinch TJ and Bijker WE (1984) The Social Construction of Facts and Artefacts: or How the Sociology of Science and the Sociology of Technology Might Benefit From Each Other. Social Studies of Science 14: 399-411.

Reich A (2011) The Transformation of Participatory Space. In: Singer JB, Hermida A, Domingo D, Heinonen A, Paulussen S, Quandt T, Reich Z, and Vujnovic M Participatory Journalism: Guarding Open Gates at Online Newspapers. Maiden, MA: Wiley-Blackwell, pp. 187-229.

Schmitz Weiss A and Domingo D (2010) Innovation Processes in Online Newsrooms as Actor-Network and Communities of Practice. New Media \& Society 12(7): 11561171.

Shoemaker PJ and Vos TP (2009) Gatekeeping Theory. New York City, NY: Routledge. Singer JB, Hermida A, Domingo D, Heinonen A, Paulussen S, Quandt T, Reich Z, and Vujnovic M (2011) Participatory Journalism: Guarding Open Gates at Online Newspapers. Maiden, MA: Wiley-Blackwell.

Singer JB (2009) Role Call: 2008 Campaign and Election Coverage on the Web Sites of Leading US Newspapers. Journalism \& Mass Communication Quarterly 86(4): 
827-843.

Singer JB and Ashman I (2009) Comment Is Free, but Facts Are Sacred: User-Generated Content and Ethical Constructs at the Guardian. Journal of Mass Media Ethics 24(1): 3-21.

Thurman N (2008) Forums for Citizen Journalists? Adoption of User Generated Content Initiatives by Online News Media. New Media \& Society 10(1): 139-157.

Williams W (1998) The Blurring of the Line Between Advertising and Journalism in the On-line Environment. In Borden D and Harvey K (eds) The Electronic Grapevine. Mahwah, NJ: Earlbaum, pp. 31-41.

Wheeler R, Christiansen C, Cameron A, Hollingshead T and Rawlins B (2010) Burnout in the Newsroom: Measuring the Effects of New Media Tasks on Journalists. Unpublished conference paper, Association for Education in Journalism and Mass Communication, Boston, MA, August 2009. 
Table 1: Response Means and Correlation with Frequency of Technology Use

\begin{tabular}{|c|c|c|c|c|}
\hline Question & Mean & $\begin{array}{l}\text { Std } \\
\text { Dev }\end{array}$ & $\begin{array}{l}\text { Freq. } \\
\text { Corr. }\end{array}$ & Sig \\
\hline \multicolumn{5}{|l|}{ Use of Technology } \\
\hline $\begin{array}{l}\text { I read most or all comments on my work } \\
\text { RQ1: Anonymity }\end{array}$ & 3.03 & 1.21 & $\mathrm{n} / \mathrm{a}$ & $\mathrm{n} / \mathrm{a}$ \\
\hline \multicolumn{4}{|l|}{ RQ2: Territoriality as gatekeeping } & 0.02 \\
\hline $\begin{array}{l}\text { Online comments should not be allowed. } \\
\text { Journalists should not respond to online }\end{array}$ & 1.65 & 0.97 & $-0.10^{*}$ & 0.02 \\
\hline $\begin{array}{l}\text { comments. } \\
\text { Journalists should respond to correct }\end{array}$ & 2.82 & 1.25 & $0.17 * *$ & 0 \\
\hline factually inaccurate comments. & 3.94 & 1.02 & 0.05 & 0.19 \\
\hline $\begin{array}{l}\text { RQ3: Social outcomes in the workplace } \\
\text { An editor has added something to my } \\
\text { article to address anticipated online } \\
\text { comments. }\end{array}$ & 11 & 0.8 & $0.10 *$ & 0.02 \\
\hline $\begin{array}{l}\text { An editor had removed something from } \\
\text { my article to avoid anticipated online } \\
\text { comments. }\end{array}$ & 1.04 & 0.74 & $0.12 * *$ & 0 \\
\hline $\begin{array}{l}\text { Online comments create distrust between } \\
\text { editors and reporters. }\end{array}$ & 1.71 & 0.72 & 0.07 & 0.1 \\
\hline $\begin{array}{l}\text { RQ4: Mutual shaping via recursive sha } \\
\text { Online comments have helped me see a } \\
\text { perspective I had not considered. }\end{array}$ & 2.64 & 0.78 & $0.26 * *$ & 0 \\
\hline $\begin{array}{l}\text { I have changed how I worked on a story } \\
\text { because of anticipated online comments. } \\
\text { Reading online comments drains time I }\end{array}$ & 1.45 & 0.79 & $0.14^{* *}$ & 0 \\
\hline $\begin{array}{l}\text { could better spend working on articles. } \\
\text { Online comments increase my job }\end{array}$ & 2.4 & 0.94 & $0.08 *$ & 0.05 \\
\hline satisfaction. & 2.17 & 0.82 & $0.39 * *$ & 0 \\
\hline
\end{tabular}

$\mathrm{DF}=582$

* Spearman's Rho Correlation is significant at the

0.05 level (2-tailed)

** Spearman's Rho Correlation is significant at the

0.01 level (2-tailed)

RQ1, RQ2: 1= strongly disagree, 5= strongly agree

RQ3, RQ4: 1= never, 5= always

"Comments" = anonymous online comments. 